\title{
Determinants of Undergraduates' Environmental Behavioral Intentions and Their Links to Socioscientific Issues Education
}

\author{
Caitlin K Kirby ${ }^{1^{*}}$
}

${ }^{1}$ University of Nebraska-Lincoln, UNITED STATES

*Corresponding Author: ckirby@unl.edu

Citation: Kirby, C. K. (2021). Determinants of undergraduates' environmental behavioral intentions and their links to socioscientific issues education. Interdisciplinary Journal of Environmental and Science Education, 17(2), e2231. https://doi.org/ 10.21601/ijese/9335

\begin{abstract}
ARTICLE INFO
ABSTRACT

Received:

16 October 2020

Socioscientific issues (SSI) education provides a framework for students to learn about controversial scientific topics such as climate change, vaccines, and genetic engineering, but rarely measures specific personal factors in student decision-making. SSI educators might benefit from building on behavior theories

Accepted:

23 November 2020 such as the Theory of Planned Behavior (TPB) and Value-Belief-Norm Theory of Environmentalism (VBN) in examining how students make decisions about different types of environmental issues. Undergraduate students ( $n=132$ ) were surveyed to investigate for which types of behavior TPB, VBN, or both theories are most effective, and to explore whether climate change knowledge was a significant predictor of behavior. Behaviors were divided into indirect behaviors with recycling as a direct behavior comparison. The combined theories of behavior best predicted behavioral intentions in regression models over either theory individually. Recycling, a direct environmental behavior, was predicted by different determinants than three indirect environmental behaviors. Climate change knowledge was not a significant predictor in any of the models. These results support the use of different behavior models for different behaviors and exploration of subjective and personal norms around environmental behavior in the SSI classroom.
\end{abstract}

Keywords: theory of planned behaviour, value-belief-norm theory, environmental behaviour, environmental citizenship, socioscientific issues

\section{INTRODUCTION}

Complex scientific issues are common sources of contention in public opinion and policy debates, requiring science students to be able to incorporate both scientific understanding and broader cultural, political, and social factors. Environmental issues, such as climate change or the use of genetically modified crops, often fall into this category. Students will need to navigate behaviors around these environmental issues (for example, by deciding whether to commute to work in a personal vehicle or via public transport) and therefore require a functional scientific literacy that allows them to integrate scientific understanding with these extraneous factors (Zeidler et al., 2005). Socioscientific issues (SSI) education provides a framework for developing functional scientific literacy in students and includes a focus on student decision making (Herman, 2015, 2018). SSI education frameworks utilize broad themes of moral and cognitive development in advancing this goal (Zeidler et al., 2005). This broad focus would benefit from an understanding of specific, measurable components of student decision making. Environmental psychology theories that may provide insight into students' behaviors are rarely featured in SSI education (Fang et al., 2019; Heimlich \& Ardoin, 2008; Herman, 2018).

To understand students' environmental behavioral intentions and provide a platform for incorporating behavior theories in SSI education, this study surveys undergraduates' behavioral intentions using two environmental psychology theories. In surveying student behavioral intentions with a theoretical basis, this study provides guidance for developing SSI instruction based on specific, measurable outcomes. The research questions framing this work are: (1) Is a combined and modified TPB and VBN Theory more effective than the individual models for predicting environmental behavioral intentions of an undergraduate student population?; (2) Do individuals' 
knowledge and gender improve the effectiveness of this model?; and (3) Based on the most predictive behavioral model, what predicts undergraduate student behavioral intentions for indirect environmental behaviors? Predictors for the group of indirect behaviors are also compared to a direct behavior.

This combined model of behavior theories is linked to the SSI education framework in order to provide SSI educators with resources in developing classroom activities, interventions, or assessments that measure determinants of students' behavioral intentions.

\section{THEORETICAL FRAMEWORKS}

SSI are controversial social dilemmas based on scientific concepts that involve complicated social and ethical implications (Sadler \& Zeidler, 2005; Zeidler et al., 2005), such as climate change (Herman, 2015; Klosterman \& Sadler, 2010; Peel et al., 2017). A focus on SSI contributes to students' functional scientific literacy, wherein students' understanding of scientific content and its links to greater society allow them to engage in robust decision making (Fang et al., 2019; Tal \& Kedmi, 2006; Zeidler et al., 2005). SSI education requires that students examine the nature of science, participate in classroom discourse, consider cultural issues, and utilize case studies (Zeidler et al., 2005). Students consider the nature of science by evaluating the strength of scientific evidence and robustness of claims based on that evidence. Cultural issues include the wider political, social, and technological context in which SSI and students are embedded. Case studies are the SSI topics used for classroom activities (Zeidler et al., 2005).

In examining SSI decision making, researchers recognize the importance of students' personal beliefs, but have not identified or measured components of those personal beliefs (Gutierez, 2015; Herman, 2015, 2018; Sadler \& Zeidler, 2005). Most SSI research also focuses on decision making processes and not the result of those processes in students' own lives-that is, their behaviors (Herman, 2018). The integration of environmental psychology theories into SSI education can fill a gap in this understanding.

The Theory of Planned Behavior (TPB) is one model that has widely been used in science education and environmental psychology, for behaviors such as recycling, environmental organization membership, and car use (Fielding et al., 2008; Kaiser et al., 2005; Summers \& Abd-El-Khalick, 2018). The TPB states that an individual's attitudes, subjective norms, and perceived behavioral control related to a specific behavior determine their intention to engage in that behavior (Ajzen, 1991).
Intentions are hypothesized to lead to behaviors. Attitudes are defined as a favorable or unfavorable evaluation of a behavior. Subjective norms describe an individual's perceptions of social pressure to engage in a behavior. Perceived behavioral control (PBC) is an individual's evaluation of whether or not they are able to engage in a behavior.

The Value-Belief-Norm Theory of Environmentalism (VBN) is a model in which an individual's values, environmental worldviews, awareness of consequences, ascription of responsibility, and personal norms impact each other in turn to result in an individual's behavior. The VBN has been used to explain a range of environmental behaviors, including recycling, voting, and willingness-topay for environmental services (Aguilar-Luzón et al., 2012; López-Mosquera \& Sánchez, 2012; Whitley et al., 2018). Biospheric, egoistic, and altruistic values are predictors for environmental worldviews and behavioral intentions (de Groot \& Steg, 2008) and have been used in the context of SSI education (Sutter et al., 2018). Biospheric values assign an intrinsic value to nature, egoistic values involve an individual maximizing the benefits of an action and minimizing costs, and altruistic values orientations focus on the costs and benefits for other people (de Groot \& Steg, 2008). Environmental worldviews are often measured with the New Environmental Paradigm, a widely used multiple-topic scale that determines whether individuals believe that humans impact the environment (Dunlap \& Van Liere, 1978). An awareness of consequences shows the extent to which individuals link their own behavior to environmental impacts. This awareness is predicted to precede an ascription of responsibility where individuals feel personally responsible for negative environmental consequences (Steg et al., 2012; P.C. Stern et al., 1999). Pro-environmental personal norms, a sense of personal obligation to act on environmental issues, is the next component of the VBN. The causal model path of the VBN is not always supported (Aguilar-Luzón et al., 2012); there may be an interaction between personal norms and egoistic or biospheric values as indicated by their relationships to each other in other models (de Groot \& Steg, 2008).

Comparisons of TPB and VBN suggest that VBN is superior at modeling simple environmental behaviors such as signing a petition, while TPB is better suited to explaining behaviors that require more effort or have high external constraints, such as reducing car use (Steg et al., 2012). Where variables from VBN and TPB have been integrated, the predictive power of these theories often improves over either theory individually (Abrahamse \& Steg, 2011; Fielding et al., 2008; Han, 2015). Examining the variables in each theory reveals how these theories 
complement each other. Attitude as conceptualized in the TPB, as costs and benefits of engaging in a behavior, is arguably present in VBN through the awareness of consequences and the broad New Environmental Paradigm. While awareness of consequences, ascription of responsibility, and personal norms within VBN describe whether an individual has the personal drive to act, PBC provides a measure of whether or not that individual feels able to act. Behavior requires both desire and ability, so a combination of these variables seems necessary in a behavior model. Indeed, personal norms have been found to be a particularly strong predictor within the VBN (Aguilar-Luzón et al., 2012; Kaiser et al., 2005; LópezMosquera \& Sánchez, 2012). Finally, subjective norms were left out of VBN because the authors suggested that environmental behaviors went against social norms (P.C. Stern et al., 1999). Since the majority of individuals in the United States now support many environmental behaviors (Kennedy, 2017), subjective norms may encourage environmental behaviors and should be included.

In addition to complementing each other, variables from the TPB and VBN relate to the SSI framework. Classroom discourse, where peers discuss the scientific processes and their own reasoning related to SSI, should impact students' subjective norms, forming students' perceptions of their peers' expectations around environmental behaviors. Examining the cultural context of SSI is related to students' values and personal norms as they explore their own identities and values in relation to broader societal impacts of SSI.

Knowledge of environmental processes and gender are additional determinants that may impact student behaviors. Educators often measure content knowledge as an outcome of educational interventions (Gifford, 2011; Klosterman \& Sadler, 2010; Peel et al., 2017). In the SSI framework, students must evaluate the strength of scientific evidence and incorporate it into their reasoning (Zeidler et al., 2005), thus requiring an understanding of the scientific processes involved. However, whether scientific knowledge affects behavior is unclear. Some studies found strong impacts of knowledge on behavior (Bord et al., 2000; Hines et al., 1987; Kaiser et al., 1999) and others found knowledge to have a limited role or none at all (Baptiste, 2018; Kollmuss \& Agyeman, 2002). Because of these inconsistencies, it is important to include scientific knowledge in attempting to predict behavioral intentions, especially with student populations.

The impact of gender on environmental attitudes, concerns, and behavior has also been inconsistent across studies. Females have been shown to be more concerned about the environment, have more favorable environmental attitudes, and/or be more likely to engage in environmental behaviors than are males (de Leeuw et al., 2015; Meinhold \& Malkus, 2005). Some recent studies have shown no impact of gender on environmental attitudes or behavior (Burn et al., 2012; Herman, 2015; Scannell \& Gifford, 2010). These inconsistencies and shifting environmental attitudes in the United States call for updated inquiry into the link between gender and environmental behavior.

\section{Environmental Behavior Typologies and Undergraduate Engagement}

This study synthesizes the range of environmental behaviors into two action types: direct and indirect. Direct behaviors, such as using public transportation and increasing home energy efficiency, reduce individuals' greenhouse gas emissions (P.C. Stern, 2000). Similar terms include individual, private sphere, household, and consumer behaviors (Chawla \& Cushing, 2007; Kenis \& Mathijs, 2012). Direct behaviors are only impactful if many individuals engage in them. Indirect behaviors, such as contacting a government official and joining an environmental organization, aim to impact the institutions through which individuals engage in environmental action (P.C. Stern, 2000). Indirect behaviors include those related to social activist movements and are also referred to as collective, public sphere, or environmental citizenship behaviors (Chawla \& Cushing, 2007; Kenis \& Mathijs, 2012). Indirect behaviors may be particularly important in creating societal-level changes in greenhouse gas emission rates (Chawla \& Cushing, 2007) and are relevant to SSI because of the emphasis in SSI on societal-level moral and ethical decision making (Lee et al., 2013; Tal \& Kedmi, 2006). Differences in direct and indirect behaviors may necessitate different behavior theories (P.C. Stern, 2000), and researchers have called for more studies examining different types of environmental behaviors (Abrahamse \& Steg, 2011).

Undergraduate students are viable audiences for SSI educational interventions because they are enrolled in institutions of higher education. Undergraduates and other young people generally report more positive environmental attitudes than older populations (Markowitz et al., 2012) and may thus be interested in improving their ability to act environmentally. Indirect behaviors may be more important for undergraduates than direct behaviors, considering that many students have less control of household responsibilities when living in university, shared, or family housing. Additionally, higher levels of education are associated with more political involvement, indicating that college students are more likely to engage in indirect behaviors than their less educated peers (Beaumont et al., 2006). However, 
Table 1. Self-reported demographic descriptors of respondents

\begin{tabular}{ll}
\hline Demographic & $\begin{array}{l}\text { Percentage of } \\
\text { Respondents }\end{array}$ \\
\hline Gender & \\
Female & $53.0 \%$ \\
Male & $41.7 \%$ \\
Genderqueer & $3.0 \%$ \\
Ethnicity & \\
White/Caucasian & $75.0 \%$ \\
Asian/Asian-American & $9.1 \%$ \\
Black/African/African-American & $5.3 \%$ \\
Latino(a)/Hispanic & $5.3 \%$ \\
Other ${ }^{1}$ & $4.5 \%$ \\
Age & Years \\
Average ( \pm std. dev) & $19.9 \pm 1.6$ \\
Range & $18-29$ \\
\hline
\end{tabular}

${ }^{1}$ Includes American Indian/Native American, Native Hawaiian/Pacific Islander, and self-reported Other

most environmental behavior measures focus on direct behaviors (Chawla \& Cushing, 2007). This study integrates components of the TPB and VBN to examine predictors for undergraduate student intentions regarding indirect environmental behaviors with a comparison to a direct environmental behavior.

\section{METHODS}

\section{Survey Participants}

Surveys were distributed to 984 students in Fall 2016 and Spring 2017 in general education science courses at a large midwestern university via an anonymous online link emailed by their instructors. A total of 132 students complete the survey sufficiently for analysis. Participation in the survey was voluntary and had no impact on students' grades, with the exception of one course in which students received an extra credit point. The response rate was higher in that course, with 30 out of 84 students (35\%) completing the survey. The courses integrated introductory physical, biological, and chemical sciences with a focus on the environment. One of the main SSI learning goals in these courses was for students to "use scientific approaches to solving problems in the natural world". Courses emphasized links between how science is connected to other kinds of knowledge and the role of science in students' own lives. Gender, age, and ethnicity were collected to characterize the population
(Table 1).

\section{Survey Development}

Studies integrating the TPB and VBN informed a model for this study to test indirect environmental behavioral intentions with a direct environmental behavior as a comparison. The survey items included TPB determinants of subjective norms, attitudes, and perceived behavioral control, VBN items related to values and personal norms, and students' understanding of climate change processes (Figure 1). The New Environmental Paradigm was not used because it contains measures of general environmental attitudes, beliefs, intentions, and behaviors (Dunlap \& Van Liere, 1978; Hawcroft \& Milfont, 2010). Attitudes, intentions, and behaviors should be specific rather than general when using them in a TPB framework (Ajzen, 1991). Awareness of consequences and ascription of responsibility from the VBN were not included in our model because they indirectly impact behavioral intentions through personal norms (Han, 2015; Kaiser et al., 2005; Klöckner, 2013) and have been shown to be non-significant in other models (Jansson et al., 2011). For use in this study, personal norms referred to a feeling of moral obligation to engage in a behavior. Subjective norms referred to perceptions of others' expectations that individuals engage in a behavior. Survey items were developed based on prior literature as described below and adapted to fit four environmental behaviors.

The four environmental behavioral intentions of writing a letter to a government official (indirect), voting for a candidate who will fight climate change (indirect), donating to an environmental organization (indirect), and recycling (direct) were chosen to capture a range of indirect environmental behaviors with a direct environmental behavior as a comparison. Recycling was chosen as the direct behavior for comparison because it has been widely studied, including in the context of the TPB and VBN (Barr et al., 2005; Carmi et al., 2015; Wynveen et al., 2012), and therefore should fit the proposed integrated TPB and VBN model well. Each of the indirect behaviors was taken or developed from prior studies on environmental behaviors (Beaumont et al., 2006; Gärling et al., 2003; Oreg \& KatzGerro, 2006). The structure of questions examining the attitudes, subjective norms, personal norms, perceived behavioral control, and behavioral intentions for these specific environmental behaviors were taken from Harland, Staats, and Wilke (1999) because they were measuring the same variables from the TPB and VBN. A four-point Likert scale was used on items developed for this survey. Other items were taken in the same format they were developed to maintain validity and reliability of previously tested scales. 


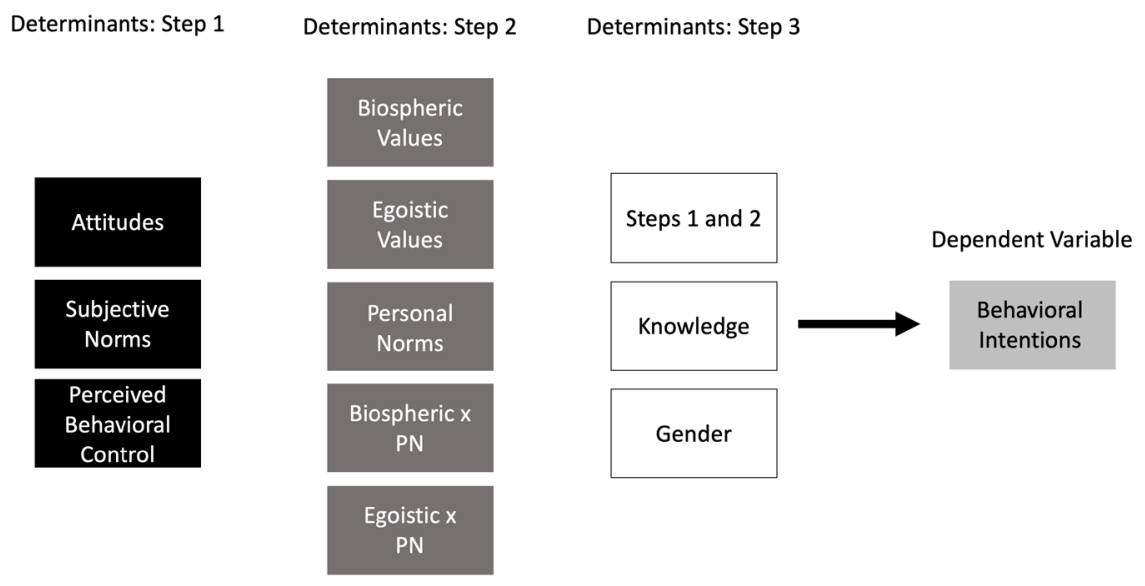

Figure 1. Hypothesized determinants of environmental behavior to be tested in a series of regressions. Items in black boxes are from TPB (Step 1), items in gray boxes are from VBN (Step 2), and knowledge and demographic items are in white boxes (Step 3, with Steps 1 and 2).

Environmental values items, measuring biospheric and egoistic values, were used in the same format as de Groot and Steg (2008) on a scale of -1 (the value is opposed to the principles that guide you) to 7 (the value is of supreme importance as a guiding principle) (Appendix). The short forms of biospheric and egoistic values were chosen based on their anticipated positive and negative correlations with environmental behavior, respectively (Steg et al., 2012).

Questions about students' scientific conceptual understanding were taken from a validated climate change concept inventory (Libarkin et al., 2018). A climate change inventory was used because it represents a significant environmental SSI. A team of experts developed this inventory based on existing measures of climate change understanding and common climate change misconceptions. Questions on this measure were subject to several validity and reliability measures, including Rasch analysis (Libarkin et al., 2018). Five questions measuring a range of climate change content knowledge were chosen (Appendix). While knowledge has been included in some environmental behavioral models (Hines et al., 1987), here it is kept separate from the TPB and VBN because it is not a determinant of these models.

\section{Scale Development}

Simple confirmatory factor analyses indicated that attitudes, perceived behavioral control, subjective norms, behavioral intentions, and personal norms items each corresponded to a single measurement scale across the four behaviors (Table 2). The Cronbach's alpha for each scale was $>0.6$ (Table 2) and all Eigenvalues were greater than 1 , indicating that the items for each variable provide an acceptable scale. Knowledge questions and values items were validated in prior studies (de Groot \& Steg, 2008; Libarkin et al., 2018).
Scale scores were created for attitudes, perceived behavioral control, subjective norms, behavioral intentions, personal norms, climate change knowledge, biospheric values, and egoistic values using the alpha command in STATA Version 15 (StataCorp, 2017). Resulting scales were an average of student responses to the items, with higher numbers indicating higher agreement, knowledge, or importance of values.

In addition to an aggregate scale across all four behaviors, three subscales were generated. Because recycling is the only direct behavior, each recycling item was separated out to create a model of direct environmental behavior. A model of determinants for the three indirect behaviors were then scaled together to create a model of indirect environmental behaviors, with resulting Cronbach's Alpha values displayed in Table 3.

\section{Regression}

Multiple ordinary least squares regression on environmental behavioral intentions was performed in STATA Version 15 (StataCorp, 2017). The first step in the series of regressions included only TPB items and the second step only the VBN items. The third step included TPB and VBN items with gender and knowledge (Figure 1). Regressions were performed of the behavioral intentions scaled together (Model 1), on the three indirect environmental behaviors as a scale (Model 2), and on recycling as a model for direct environmental behavior (Model 3), voting for a candidate who will fight climate change as a climate-specific behavior (Model 4).

\section{RESULTS}

Overall, students reported favorable attitudes towards the environmental behaviors (Figure 2). Attitudes and determinants towards indirect environmental behaviors were lower across all scales than they were for recycling. 
Table 2. Factor loadings for environmental behavior determinants

$\begin{array}{lll}\text { Theory and Item } & \text { Factor Loadings } \\ \text { Construct } & & \end{array}$

TPB: Attitude I think recycling is important

I think writing to a government official about an environmental issue is important

I think giving money to an environmental organization is important

I think voting for a candidate who will fight climate change is important

TPB: Perceived If I wBehavioraluld recycle during the next 6 months 0.679 Behavioral Control

If I wanted, I could write to a government official about an environmental issue in the next 6 months

If I wanted, I could give money to an environmental organization in the next 6 months

If I wanted, I could vote for a candidate who will fight climate change in the next election

TPB:

Subjective Norm
People who are important to me expect me to recycle

People who are important to me expect me to write to a government official about an environmental issue

People who are important to me expect me to give money to an environmental organization

People who are important to me expect me to vote for a candidate who will fight climate change

VBN: Personal I feel a personal obligation to recycle

Norm

I feel a personal obligation to write to a government official about an environmental issue

I feel a personal obligation to give money to an environmental organization

I feel a personal obligation to vote for a candidate who will fight climate change

TPB and VBN: I intend to, always or in most instances, recycle in the next 6 months

Behavioral Intention

I intend to write to a government official about an environmental issue in the next 6 months

I intend to give money, even a small amount, to an environmental organization in the next 6 months

I intend to vote for a candidate who will fight climate change in the next election

Each item for the behaviorants of TPB and VBN were factored together to ensure the measures formed a valid scale. Factor loadings below 0.290 are suppressed.

Students reported slightly stronger average biospheric values of 4.6 than egoistic values with an average of 4.1 on the scale from -1 to 7 . On average, students answered 2 of the 5 climate change questions correctly.

The results of the multiple ordinary least squares regression of behavioral intentions on these scaled variables, climate change understanding, and gender is shown in Table 4. Three steps of regression models were utilized to investigate the effectiveness of the combination of TPB, VBN, and demographics over each theory alone. 
Table 3. Cronbach's alpha for scales of indirect environmental behavior items

\begin{tabular}{ll}
\hline Indirect Environmental Behavior Scale & $\begin{array}{l}\text { Cronbach's } \\
\text { Alpha }\end{array}$ \\
\hline Attitudes & 0.779 \\
Personal Norms & 0.668 \\
Subjective Norms & 0.769 \\
Perceived Behavioral Control & 0.622 \\
Behavioral Intentions & 0.635 \\
Individual factor loadings for items were all $>0.32$ and Eigenvalues of \\
scales were $>1$
\end{tabular}

To investigate the differences in determinants for indirect and direct behaviors, three models were used. Model 1 included all four environmental behaviors, Model 2 included three indirect environmental behaviors of voting for a candidate who will fight climate change, donating money to an environmental organization, and contacting a government official about an environmental issue and model 3 consisted of recycling only as a direct environmental behavior. The sample sizes of the regression models satisfy the ratio rules of thumb to have at least 10 participants per independent variable (Van Voorhis \& Morgan, 2007).

In all models, the $\mathrm{R}^{2}$ value improved significantly with the combined model over the VBN or TPB. Gender, biospheric values, and climate change knowledge were not significant in any of the models. Subjective norms were a significant predictor of behavioral intentions in all models. Personal norms were a significant predictor of behavioral intentions for Model 2 with the indirect behaviors. PBC was a significant predictor of behavioral intentions for Model 1 with all behaviors and Model 3 with recycling. Attitudes were only significant in the combined model with the indirect climate behavior. Finally, egoistic values showed significance in some of the models, and the interaction of egoistic values and personal norms was a significant predictor of behavioral intentions in Model 1 with all behaviors. In Model 1, subjective norms, PBC, and the interaction of egoistic values and personal norms were positively related to students' behavioral intentions; egoistic values significantly decreased students' behavioral intentions. Indirect environmental behavioral intentions in Model 2 were predicted only by subjective norms and personal norms. Recycling intentions in Model 3 were predicted only by subjective norms and PBC.

\section{DISCUSSION}

The TPB and VBN appear to be useful theories for conceptualizing undergraduate students' environmental behaviors, with items in the combined TPB and VBN model explaining $49-77 \%$ of variation in students' environmental behavioral intentions. The full combined model was more successful at predicting students' behavioral intentions than either model individually, satisfying research question one. Overall, students reported stronger intentions to engage in recycling behavior than the indirect environmental behaviors. This indicates the importance of exploring indirect environmental behaviors in the classroom to equip students to address the broader implications of SSI.

\section{Environmental Behavior Determinants}

In Model 1 with all four behaviors, subjective norms, PBC, egoistic values, and the interaction of egoistic values with personal norms were significant predictors of behavioral intentions. Egoistic values alone had a negative correlation with environmental behavioral intentions as

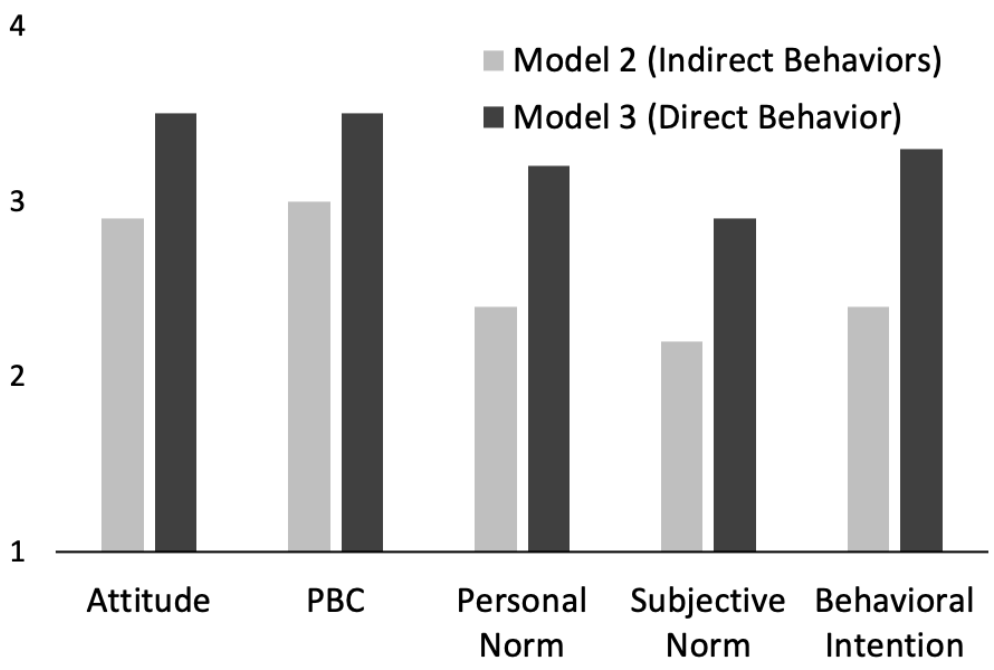

Figure 2. Mean responses for scale items. Items are on a 4-point Likert scale with 4 indicating strong agreement. Model 2 displays the average of results for the three indirect behaviors and Model 3 is recycling items only. Model 1 consists of Models 2 and 3 averaged 


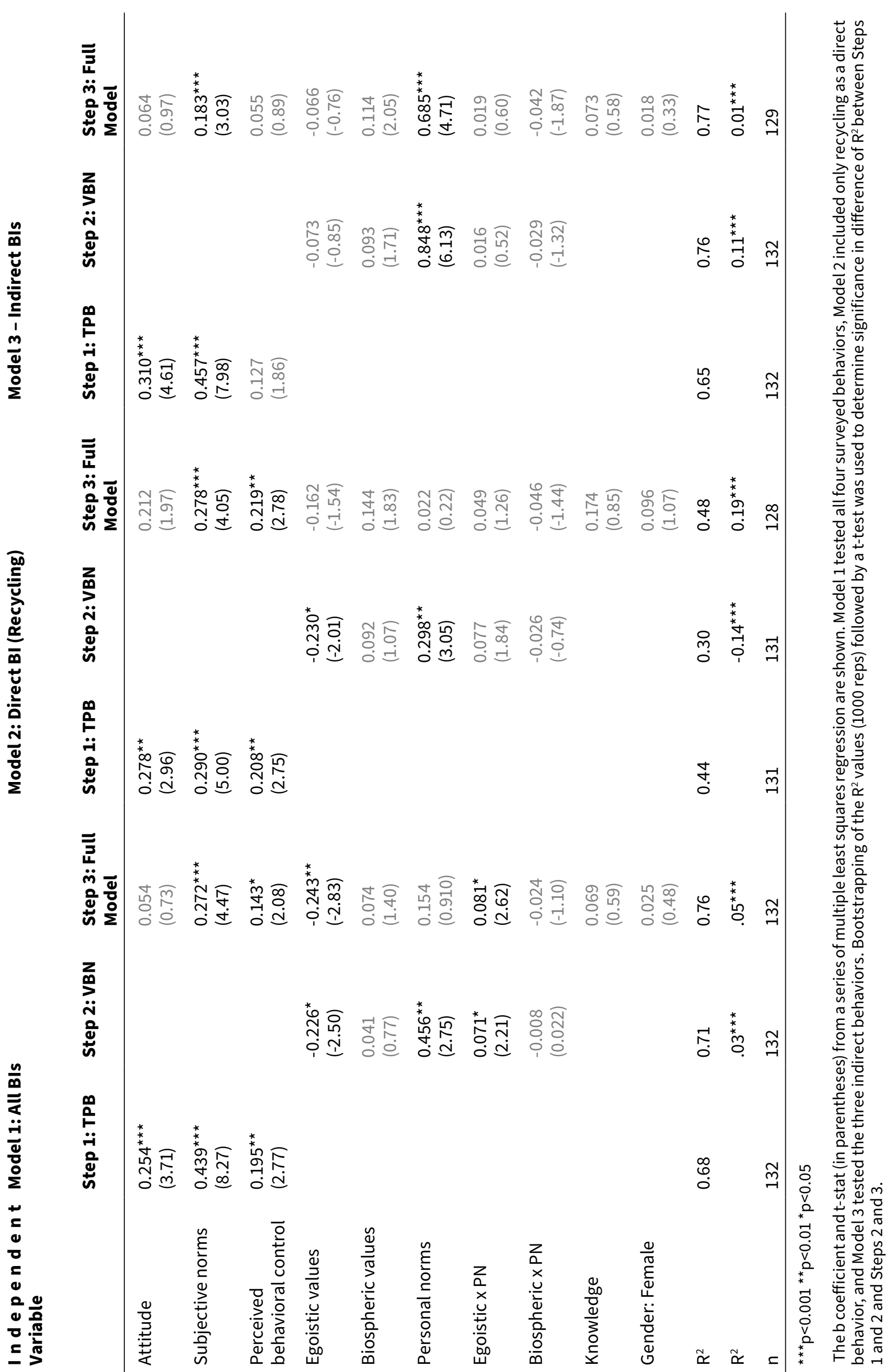


predicted (de Groot \& Steg, 2008). However, individuals who value their own status and also feel obligated to engage in environmental behaviors have amplified intentions to do so over those with strong personal norms and low egoistic values. Based on the current study, egoistic values could support environmental behaviors when individuals' environmental personal norms are activated.

Students' knowledge of climate change processes, biospheric values, and gender were not significant in influencing undergraduate students' behavioral intentions. This answers research question two and supports the use of environmental behavior models without the inclusion of gender and climate change knowledge. SSI education research contextualizes the finding that knowledge was not a significant predictor of behavioral intentions. Students often incorporate their personal beliefs when evaluating scientific information (Zeidler et al., 2005), but the threshold model of content knowledge transfer suggests that once students receive a threshold level of scientific knowledge content, their scientific reasoning in SSI argumentation improves (Sadler \& Fowler, 2006). However, there may not be a direct link between argumentation and decision making or behavior (Acar et al., 2010). So while content knowledge is helpful, SSI instruction requires content beyond scientific knowledge to improve students' functional scientific literacy, such as a consideration of their own personal and subjective norms. An additional factor in the role of knowledge is the type of knowledge measured in this survey, which was related to the concepts of climate change. Knowledge of how to engage in behaviors or which actions may result in environmental change is another potentially important link in students' behaviors (Hines et al., 1987). Attitudes were only significant in the TPB only models. This demonstrates that perhaps items from the VBN are more important than attitudes, which have been found not significant in other models as well (López-Mosquera \& Sánchez, 2012). Finally, biospheric values may have an indirect, rather than direct, impact on behavioral intentions as hypothesized by VBN.

\section{Determinants for Indirect Environmental Behaviors}

Regression results across Models 2 and 3 address research question three and show differences in indirect environmental behaviors with the comparison of a direct environmental behavior, recycling. For the three indirect behaviors in Model 2, the VBN alone was a stronger predictor of intentions than the TPB. This could be explained because VBN was designed with a range of indirect behaviors in mind as a measure of ecological citizenship (P.C. Stern et al., 1999). The combined items from VBN and TPB were the strongest predictor for the indirect behaviors scaled together, with personal norms and subjective norms as the only two significant determinants of indirect environmental behavioral intentions. Thus, the integration of personal norms into the TPB may be particularly relevant when examining indirect behaviors. PBC appears not to impact indirect environmental behaviors in the same way as recycling, which is supported by a prior study on students' environmental activism (Fielding et al., 2008).

In Model 3, TPB better explains recycling behavioral intentions than VBN. This is in line with theoretical predictions and prior studies; recycling requires the availability of recycling facilities, causing PBC to have a large impact on behavioral intentions (Barr et al., 2005; Carmi et al., 2015). Recycling here serves as a single direct behavior comparison, but similar results were found where PBC was impactful for several direct environmental behaviors in high school students (de Leeuw et al., 2015). These differences between Models 2 and 3 indicate that personal norms may be more important in developing indirect environmental behaviors, and PBC may be more important in developing direct environmental behaviors.

\section{IMPLICATIONS IN THE CLASSROOM}

The significant determinants of environmental behavioral intentions in this study can guide educators in engaging students around environmental behaviors. First, subjective norms (perceived social approval of behaviors) appear to impact students' environmental behavioral intentions. Subjective norms may be activated by discussing environmental behaviors with peers, particularly when some students already engage in environmental behaviors, or by educators demonstrating that they engage in environmental actions (de Leeuw et al., 2015). In a meta-analysis, this social modeling has been shown to be among the intervention types with the largest effect sizes on individual environmental behavior (Osbaldiston \& Schott, 2012). Subjective norms may already be activated in SSI classrooms through classroom discourse, with small group discussions and encouraging students to take perspectives of SSI decision makers (Tal \& Kedmi, 2006). Interventions targeting students' subjective norms should measure pre- and post-perceptions of subjective norms and efficacy in changing behavior.

Second, personal norms (feelings of obligation to engage in a behavior) appear to play a strong role in indirect environmental behavioral intentions. To strengthen personal norms, students might be offered the opportunity to engage in contemplative and reflective learning practices where they consider their own thoughts, feelings, and desired actions within 
environmental systems (Blackmore, 2007; M. J. Stern et al., 2014). Examples of such activities in SSI classrooms include students journaling about or discussing their personal feelings and reactions to SSI (Klosterman \& Sadler, 2010; Lee et al., 2013). SSI education researchers should evaluate personal norms as a component of students' understanding of their roles in environmental, cultural, and political systems.

A striking result of this study and others is the lack of students' engagementin indirectenvironmentalbehaviors (Kenis \& Mathijs, 2012; Markowitz et al., 2012). Teaching students about their role in civic processes can improve students' intentions to engage in citizenship behaviors such as voting or contacting an official (Beaumont et al., 2006). However, even when courses focus on social aspects of environmental issues, students may not feel personally accountable or able to act on those issues (Lee et al., 2013). This again highlights the importance of examining students' own perspectives and roles with personal norms in discussing indirect environmental behaviors. SSI classroom interventions often focus on high-level processes such as national policy development and modeling global carbon cycling (Klosterman \& Sadler, 2010; Zangori et al., 2017). Integrating these high-level discussions and models with individuals' roles in sociopolitical systems may link the broad with the personal and provide students a pathway for identifying indirect actions.

An understanding of behavior theories such as TPB and VBN and their relationship to students' environmental behaviors can provide guidance for SSI educators. While there is an understanding of some decision making processes within SSI, the analyses of environmental behaviorshereprovide specific, quantitative determinants that can be used to develop educational interventions and to measure the impact of those interventions. This study builds on research examining the TPB and VBN with a range of environmental behaviors and suggests that different models are needed in predicting direct and indirect environmental behaviors. Future research that incorporates additional direct and indirect environmental behaviors, larger samples across additional institutions, or develops interventions based on this work would further strengthen the connection between SSI, TPB, and VBN. In offering activities that allow students to explore their own norms towards environmental behavior and the norms of their peers, SSI educators may contribute to an environmentally active populace that can implement climate solutions in years to come.

\section{LIMITATIONS}

The survey methodology used here has several limitations that are worth noting when interpreting these results. The survey measured behavioral intentions rather than actual behaviors. The relationship between behavioral intentions and behaviors is inconsistent, with some studies showing strong relationships (Kaiser et al., 2005; Levine \& Strube, 2012) and others showing weak relationships (Gifford \& Nilsson, 2014; Hassan et al., 2016; Herman, 2018). In addition, the role of knowledge has been shown to be more impactful in studies measuring actual behaviors (Hines et al., 1987). When possible, future studies should consider ways to measure actual indirect behaviors. Due to survey length concerns, only one direct behavior was used as a comparison to the indirect behaviors. Recycling is not a representative direct behavior, and recycling facilities are widely available in the United States, including on the college campus where this survey took place; therefore, it is a more common direct behavior than others (Barr et al., 2005). However, because of its prevalence in prior studies and use in TPB and VBN models, it provides a useful point of comparison for the purposes of this study. The comparison presented here does not allow for an understanding of the path model between variables in the TPB and VBN; sample size concerns prevented the use of structural equation models, which future researchers should consider to better understand the relationships between these models. The United States context also influences the indirect behaviors, such as voting for a political candidate, because the structure of its political system allows public engagement.

\section{REFERENCES}

Abrahamse, W., \& Steg, L. (2011). Factors related to household energy use and intention to reduce it: The role of psychological and socio-demographic variables. Human Ecology Review, 18(1), 30-40.

Acar, O., Turkmen, L., \& Roychoudhury, A. (2010). Student difficulties in socio-scientific argumentation and decision-making research findings: Crossing the borders of two research lines. International Journal of Science Education, 32(9), 1191-1206. https://doi. org/10.1080/09500690902991805

Aguilar-Luzón, M. del C., García-Martínez, J. M. Á., CalvoSalguero, A., \& Salinas, J. M. (2012). Comparative study between the Theory of Planned Behavior and the ValueBelief-Norm model regarding the environment, on Spanish housewives' recycling behavior. Journal of Applied Social Psychology, 42(11), 2797-2833. https://doi.org/10.1111/ j.1559-1816.2012.00962.x

Ajzen, I. (1991). The Theory of Planned Behavior. Organizational Behavior and Human Decision Processes, 50, 179-211.

Baptiste, A. K. (2018). Climate change knowledge, concerns, and behaviors among Caribbean fishers. Journal of 
Environmental Studies and Sciences, 8(1), 51-62. https://doi. org/10.1007/s13412-017-0434-9

Barr, S., Gilg, A., \& Ford, N. (2005). Defining the multi-dimensional aspects of household waste management: A study of reported behavior in Devon. Resources, Conservation and Recycling, 45(2), 172-192. https://doi.org/10.1016/j. resconrec.2004.12.007

Beaumont, E., Colby, A., Ehrlich, T., \& Torney-Purta, J. (2006). Promoting political competence and engagement in college students: An empirical study. Journal of Political Science Education, 2(3), 249-270. https://doi. org/10.1080/15512160600840467

Blackmore, C. (2007). What kinds of knowledge, knowing and learning are required for addressing resource dilemmas?: a theoretical overview. Environmental Science and Policy, 10(6), 512-525. https://doi.org/10.1016/j.envsci.2007.02.007

Bord, R. J., O'Connor, R. E., \& Fisher, A. (2000). In what sense does the public need to understand global climate change? Public Understanding of Science. 9, 205-218. https://doi. org/10.1088/0963-6625/9/3/301

Burn, S. M., Winter, P. L., Hori, B., \& Silver, N. C. (2012). Gender, ethnic identity, and environmental concern in Asian Americans and European Americans. Society for Human Ecology, 19(2), 136-145.

Carmi, N., Arnon, S., \& Orion, N. (2015). Seeing the forest as well as the trees: general vs. specific predictors of environmental behavior. Environmental Education Research, 21(7), 10111028. https://doi.org/10.1080/13504622.2014.949626

Chawla, L., \& Cushing, D. F. (2007). Education for strategic environmental behavior. Environmental Education Research, 13(4), 437-452. https://doi.org/10.1080/13504620701581539

de Groot, J. I. M., \& Steg, L. (2008). Value orientations to explain beliefs related to environmental significant behavior: How to measure egoistic, altruistic, and biospheric value orientations. Environment and Behavior, 40(3), 330-354. https://doi.org/10.1177/0013916506297831

de Leeuw, A., Valois, P., Ajzen, I., \& Schmidt, P. (2015). Using the theory of planned behavior to identify key beliefs underlying pro-environmental behavior in high-school students: Implications for educational interventions. Journal of Environmental Psychology, 42, 128-138. https:// doi.org/10.1016/j.jenvp.2015.03.005

Dunlap, R. E., \& Van Liere, K. D. (1978). The "New Environmental Paradigm." Journal of Environmental Education, 9(4), 10-19. https://doi.org/10.1080/00958964.1978.10801875

Fang, S. C., Hsu, Y. S., \& Lin, S. S. (2019). Conceptualizing socioscientific decision making from a review of research in science education. International Journal of Science and Mathematics Education, 17(3), 427-448. https://doi. org/10.1007/s10763-018-9890-2

Fielding, K. S., McDonald, R., \& Louis, W. R. (2008). Theory of planned behaviour, identity and intentions to engage in environmental activism. Journal of Environmental Psychology, 28(4), 318-326. https://doi.org/10.1016/j. jenvp.2008.03.003

Gärling, T., Fujii, S., Gärling, A., \& Jakobson, C. (2003). Moderating effects of social value orientation on determinants of proenvironmental behavior intention. Journal of Environmental Psychology, 23, 1-9. https://doi. org/10.1016/S0272-4944(02)00081-6

Gifford, R. (2011). The dragons of inaction: Psychological barriers that limit climate change mitigation and adaptation. American Psychologist, 66(4), 290-302. https:// doi.org/10.1037/a0023566

Gifford, R., \& Nilsson, A. (2014). Personal and social factors that influence pro-environmental concern and behaviour: A review. International Journal of Psychology, 49(3), 141-157. https://doi.org/10.1002/ijop.12034

Gutierez, S. B. (2015). Integrating socio-scientific issues to enhance the bioethical decision-making skills of high school students. International Education Studies, 8(1), 142151. https://doi.org/10.5539/ies.v8n1p142

Han, H. (2015). Travelers' pro-environmental behavior in a green lodging context: Converging value-belief-norm theory and the theory of planned behavior. Tourism Management, 47, 164-177. https://doi.org/10.1016/j.tourman.2014.09.014

Harland, P., Staats, H., \& Wilke, H. A. M. (1999). Explaining proenvironmental intention and behavior by personal norms and the theory of planned behavior. Journal of Applied Social Psychology, 29(12), 2505-2528.

Hassan, L. M., Shiu, E., \& Shaw, D. (2016). Who says there is an intention-behaviour gap? Assessing the empirical evidence of an intention-behaviour gap in ethical consumption. Journal of Business Ethics, 136(2), 219-236. https://doi. org/10.1007/s10551-014-2440-0

Hawcroft, L. J., \& Milfont, T. L. (2010). The use (and abuse) of the new environmental paradigm scale over the last 30 years: A meta-analysis. Journal of Environmental Psychology, 30(2), 143-158. https://doi.org/10.1016/j.jenvp.2009.10.003

Heimlich, J., \& Ardoin, N. (2008). Understanding behavior to understand behavior change: a literature review. Environmental Education Research, 14(3), 215-237. https:// doi.org/10.1080/13504620802148881

Herman, B. C. (2015). The influence of global warming science views and sociocultural factors on willingness to mitigate global warming. Science Education, 99(1), 1-38. https://doi. org/10.1002/sce.21136

Herman, B. C. (2018). Students' environmental NOS views, compassion, intent, and action: Impact of place-based socioscientific issues instruction. Journal of Research in Science Teaching, 55(4), 600-638. https://doi.org/10.1002/ tea. 21433

Hines, J. M., Hungerford, H. R., \& Tomera, A. N. (1987). Analysis and synthesis of research on responsible environmental behavior: A meta-analysis. Journal of Environmental Education, 18(2), 1-8. https://doi.org/10.1080/00958964.19 87.9943482

Jansson, J., Marell, A., \& Nordlund, A. (2011). Exploring consumer adoption of a high involvement eco-innovation using valuebelief-norm theory. Journal of Consumer Behaviour, 10(1), 51-60. https://doi.org/10.1002/cb.346

Kaiser, F. G., Hübner, G., \& Bogner, F. X. (2005). Contrasting the Theory of Planned Behavior With the Value-Belief-Norm Model in Explaining Conservation Behavior. Journal of Applied Social Psychology, 35(10), 2150-2170.

Kaiser, F. G., Wölfing, S., \& Fuhrer, U. (1999). Environmental attitude and ecological behaviour. Journal of Environmental Psychology, 19, 1-19. https://doi. org/10.1108/17471111311307787

Kenis, A., \& Mathijs, E. (2012). Beyond individual behaviour change: the role of power, knowledge and strategy in tackling climate change. Environmental Education Research, 18(1), 45-65. https://doi.org/10.1080/13504622.2011.57631 5

Klöckner, C. A. (2013). A comprehensive model of the psychology of environmental behaviour-A meta-analysis. 
Global Environmental Change, 23(5), 1028-1038. https://doi. org/10.1016/j.gloenvcha.2013.05.014

Klosterman, M. L., \& Sadler, T. D. (2010). Multi-level assessment of scientific content knowledge gains associated with socioscientific issues-based instruction. International Journal of Science Education, 32(8), 1017-1043. https://doi. org/10.1080/09500690902894512

Kollmuss, A., \&Agyeman, J. (2002). Mind the Gap: Why do people act environmentally and what are the barriers to proenvironmental behavior? Environmental Education Research, 8(3), 239-260. https://doi.org/10.1080/13504620220145401

Lee, H., Yoo, J., Choi, K., Kim, S. W., Krajcik, J., Herman, B. C., \& Zeidler, D. L. (2013). Socioscientific Issues as a Vehicle for Promoting Character and Values for Global Citizens. International Journal of Science Education, 35(12), 20792113. https://doi.org/10.1080/09500693.2012.749546

Levine, D. S., \& Strube, M. J. (2012). Environmental attitudes, knowledge, intentions and behaviors among college students. Journal of Social Psychology, 152(3), 308-326. https://doi.org/10.1080/00224545.2011.604363

Libarkin, J. C., Gold, A. U., Harris, S. E., McNeal, K. S., \& Bowles, R. P. (2018). A new, valid measure of climate change understanding: associations with risk perception. Climatic Change, 150(3-4), 403-416. https://doi.org/10.1007/s10584018-2279-y

López-Mosquera, N., \& Sánchez, M. (2012). Theory of planned behavior and the value-belief-norm theory explaining willingness to pay for a suburban park. Journal of Environmental Management, 113, 251-262. https://doi. org/10.1016/j.jenvman.2012.08.029

Markowitz, E. M., Goldberg, L. R., Ashton, M. C., \& Lee, K. (2012). Profiling the "pro-environmental individual": A personality perspective. Journal of Personality, 80(1), 81-111. https:// doi.org/10.1111/j.1467-6494.2011.00721.x

Meinhold, J. L., \& Malkus, A. J. (2005). Adolescent environmental behaviors: Can knowledge, attitudes and self-efficacy make a difference? Environment and Behavior, 37(4), 511-532. https://doi.org/10.1177/0013916504269665

Oreg, S., \& Katz-Gerro, T. (2006). Predicting proenvironmental behavior cross-nationally. Environment and Behavior, 38(4), 462-483. https://doi.org/10.1177/0013916505286012

Osbaldiston, R., \& Schott, J. P. (2012). Environmental sustainability and behavioral science: Metaanalysis of proenvironmental behavior experiments. Environment and Behavior, 44(2), 257-299. https://doi. org/10.1177/0013916511402673

Peel, A., Sadler, T. D., Kinslow, A. T., Zangori, L., \& Friedrichsen, P. (2017). Climate change as an issue for socio-scientific issues teaching and learning. In D. P. Shepardson, A. Roychoudhury, \& A. S. Hirsch (Eds.), Teaching and Learning about Climate Change: A Framework for Educators (pp. 153165). Routledge.

Sadler, T. D., \& Fowler, S. R. (2006). A threshold model of content knowledge transfer for socioscientific argumentation. Science Education, 90(6), 986-1004. https://doi.org/10.1002/ sce. 20165

Sadler, T. D., \& Zeidler, D. L. (2005). Patterns of informal reasoning in the context of socioscientific decision making. Journal of Research in Science Teaching, 42(1), 112-138. https://doi.org/10.1002/tea.20042

Scannell, L., \& Gifford, R. (2010). The relations between natural and civic place attachment and pro-environmental behavior. Journal of Environmental Psychology, 30(3), 289-
297. https://doi.org/10.1016/j.jenvp.2010.01.010

Stern, M. J., Powell, R. B., \& Hill, D. (2014). Environmental education program evaluation in the new millennium: What do we measure and what have we learned? Environmental Education Research, 20(5), 581-611. https://doi.org/10.1080 /13504622.2013.838749

Stern, P. C. (2000). New environmental theories: Toward a coherent theory of environmentally significant behavior. Journal of Social Issues, 56(3), 407-424. https://doi. org/10.1111/0022-4537.00175

Stern, P. C., Dietz, T., Abel, T., Guagnano, G. A., \& Kalof, L. (1999). A value-belief-norm theory of support for social movements: The case of environmentalism. Human Ecology Review, 6(2), 81-97. https://doi.org/10.2307/2083693

Summers, R., \& Abd-El-Khalick, F. (2018). Development and validation of an instrument to assess student attitudes toward science across grades 5 through 10 . Journal of Research in Science Teaching, 55(2), 172-205. https://doi. org/10.1002/tea.21416

Sutter, A. M., Dauer, J. M., \& Forbes, C. T. (2018). Application of construal level and value-belief norm theories to undergraduate decision-making on a wildlife socioscientific issue. International Journal of Science Education, 40(9), 1058-1075. https://doi.org/10.1080/09500693.2018.1 467064

Tal, T., \& Kedmi, Y. (2006). Teaching socioscientific issues: Classroom culture and students' performances. Cultural Studies of Science Education, 1(4), 615-644. https://doi. org/10.1007/s11422-006-9026-9

Van Voorhis, C. R. W., \& Morgan, B. L. (2007). Understanding power and rules of thumb for determining sample sizes. Tutorials in Quantitative Methods for Psychology, 3(2), 43-50. https://doi.org/10.20982/tqmp.03.2.p043

Whitley, C. T., Takahashi, B., Zwickle, A., Besley, J. C., \& Lertpratchya, A. P. (2018). Sustainability behaviors among college students: An application of the VBN theory. Environmental Education Research, 24(2), 245-262. https:// doi.org/10.1080/13504622.2016.1250151

Wynveen, C. J., Kyle, G. T., \& Tarrant, M. A. (2012). Study abroad experiences and global citizenship: Fostering proenvironmental behavior. Journal of Studies in International Education, 16(4), 334-352. https://doi. org/10.1177/1028315311426782

Zangori, L., Peel, A., Kinslow, A., Friedrichsen, P., \& Sadler, T. D. (2017). Student development of model-based reasoning about carbon cycling and climate change in a socio-scientific issues unit. Journal of Research in Science Teaching, 54(10), 1249-1273. https://doi.org/10.1002/tea.21404

Zeidler, D. L., Sadler, T. D., Simmons, M. L., \& Howes, E. V. (2005). Beyond STS: A research-based framework for socioscientific issues education. Science Education, 89(3), 357-377. https:// doi.org/10.1002/sce. 20048 


\section{APPENDIX}

Climate change questions were taken from Libarkin et al. (2018) with correct answers in bold. Biospheric (\#1-3) and egoistic (\#4-6) values items were adapted from de Groot and Steg (2008).

1. How has the amount of carbon dioxide in the atmosphere changed since the start of the Industrial Revolution 150 years ago?

A. The amount of carbon dioxide has remained the same.

B. The amount of carbon dioxide has decreased.

C. The amount of carbon dioxide has increased.

D. I do not know.

2. Which of the following best describes how plants take in carbon dioxide?

A. Plants take in carbon dioxide from rain.

B. Plants take in carbon dioxide from sunlight.

C. Plants take in carbon dioxide from air.

D. Plants take in carbon dioxide from soil.

E. I do not know.

3. Which is the most common form of radiation given off by Earth's surface?

A. The Earth's surface mostly gives off visible radiation.

B. The Earth's surface mostly gives off infrared radiation.

C. The Earth's surface mostly gives off ultraviolet radiation.

D. Earth's surface does not give off radiation.

E. I do not know.

4. Which is the best definition of a positive feedback loop in the climate system?

A. A change in the climate system leads to a response that benefits climate change.

B. A change in the climate system leads to a response that slows down climate change.

C. A change in the climate system leads to a response that speeds up climate change.

D. A change in the climate system leads to a response that harms climate change.

E. I do not know.

5. Averaged over long time periods, how does the amount of energy arriving from space compare to the amount of energy leaving Earth?

A. The amount of energy arriving from space is greater than the amount of energy leaving Earth.

B. The amount of energy arriving from space is less than the amount of energy leaving Earth.

C. The amount of energy arriving from space is roughly equal to the amount of energy leaving Earth.

D. I do not know.

Below you will find 3 values. Behind each value there is a short explanation concerning the meaning of the value. Could you please rate how important each value is for you AS A GUIDING PRINCIPLE IN YOUR LIFE?

The rating scale is as follows:

0 means the value is not important at all; it is not relevant as a guiding principle in your life

3 means the value is important

6 means the value is very important

-1 means the value is opposed to the principles that guide you

7 means the value is of supreme importance as a guiding principle in your life

Your scores can vary from -1 up to 7 . The higher the number $(-1,0,1,2,3,4,5,6,7)$, the more important the value is as a guiding principle in YOUR life.

UNITY WITH NATURE: fitting into nature

RESPECTING THE EARTH: harmony with other species

PROTECTING THE ENVIRONMENT: preserving nature

INFLUENTIAL: having an impact on people and events

WEALTH: material possessions, money

AUTHORITY: the right to lead or command 